\title{
Overcoming knowledge barriers to adaptation using a decision support framework
}

\author{
J. P. Palutikof ${ }^{1}$ (D) - Anne M. Leitch ${ }^{1} \cdot$ D. Rissik ${ }^{1}$ • \\ S. L. Boulter ${ }^{1}$ - M. J. Campbell ${ }^{1}$. \\ A. C. Perez Vidaurre ${ }^{1}$ - S. Webb ${ }^{1}$ - Fahim N. Tonmoy ${ }^{1,2}$
}

Received: 12 November 2017 / Accepted: 5 March 2018 /Published online: 19 March 2018

(C) The Author(s) 2018

\begin{abstract}
A decision support and information delivery framework, CoastAdapt, has been built to support the coastal adaptation community in Australia to take action to address climate change and sea-level rise. For such frameworks to be useful, used and long-lived, their development requires collaboration between creators and potential users. Therefore, we undertook extensive consultation throughout the design, build and evaluation. In this paper, we explore those aspects of the consultation that focused on understanding and addressing user needs and how CoastAdapt could best provide support to effectively carry out adaptation planning and action. The first step was to identify, through an online survey and workshops, the knowledge gaps and barriers that could be addressed by CoastAdapt. The responses fed into the design and build, together with additional feedback from users on the layout and content. Following release of the beta version, further comments from users were collected and scrutinised to identify modifications that could increase relevance and utility. Finally, test cases were carried out to understand whether CoastAdapt is truly fit for purpose in addressing 'real-world' adaptation situations. The end result is a supportive framework for coastal adaptation that will require constant monitoring and updating to ensure it remains fit for purpose given Australia's rapidly evolving adaptation landscape.
\end{abstract}

This article is part of a Special Issue on 'Decision Support Tools for Climate Change Adaptation' edited by Jean Palutikof, Roger Street and Edward Gardiner.

Electronic supplementary material The online version of this article (https://doi.org/10.1007/s10584-0182177-3) contains supplementary material, which is available to authorized users.

J. P. Palutikof

j.palutikof@griffith.edu.au

1 National Climate Change Adaptation Research Facility, Griffith University, Gold Coast, Queensland 4222, Australia

2 Griffith Centre for Coastal Management, Griffith University, Gold Coast, Queensland 4222, Australia 


\section{Introduction}

Australia's population, and associated infrastructure, is concentrated along the coast (Chen and McAneney 2006; DCC 2009), especially coastal cities (The World Bank Group 2017), hence making the nation vulnerable to the effects of sea-level rise and its effects on erosion, storm surge and inundation (Fletcher et al. 2016; McInnes et al. 2016; Wang et al. 2016). It is estimated that existing residential buildings to the value of $\mathrm{A} \$ 63$ billion (replacement) are potentially at risk of inundation from a 1.1-m sea-level rise (DCC 2009). These risks may be accompanied by storm intensification, including tropical cyclones and East coast lows (Walsh et al. 2016), although recent work has suggested that both storm frequency and intensity may decline due to climate change (Knutson et al. 2015; Walsh et al. 2016).

In recognition of present-day and future risks from climate change and sea-level rise, the National Climate Change Adaptation Research Facility (NCCARF) with support from the Australian Government developed a decision support and information delivery framework, CoastAdapt (coastadapt.com.au), aimed at managers in coastal local councils, utilities and businesses, as well as their stakeholders, for example in community groups (Palutikof et al. submitted). Responsibility for coastal adaptation falls mainly to local councils (Measham et al. 2011; Baker et al. 2012; Harman et al. 2015; Mees 2017), which are generally under-resourced in terms of financial and human capacity. Some have only begun to consider the risks of climate change and sea-level rise, and some have moved to plan and build capability (Mukheibir et al. 2013; Webb et al. 2013), but examples of adaptation plans that have been carried through to implementation are rare (Gurran et al. 2013). Against this background, the aim was that CoastAdapt would deliver knowledge to underpin effective decision-making to support adaptation at all stages, from simple recognition of the risks through to planning, delivery, monitoring and evaluation of adaptation projects.

Many adaptation barriers are not directly related to knowledge about climate change per se (Sciulli 2013; Oberlack 2017). Waters et al. (2014) identify 50 distinct barriers grouped into five categories: governance, policy, information, resources and psycho-social. Commonly identified barriers include lack of or inconsistent leadership, inadequate knowledge of risks and responses, lack of financial resources, competing objectives and values and lack of institutional support (Barnett et al. 2015; Henstra 2017; Herrmann and Guenther 2017). At the transition between planning and action, barriers include perception of the risk (Mills et al. 2016), capacity to utilise scientific knowledge (Temby et al. 2016) and lack of adaptive capacity (Kiem and Austin 2013; Kiem et al. 2014; Marshall and Stokes 2014).

Work on CoastAdapt began in October 2014, and the project was completed in February 2017. Within that period, the initial design and build for the beta version took from October 2014 to June 2016, when the beta version was released for public consultation and review for 4 months. Following analysis of review comments, changes and additions were made and a governmentapproved version was released in March 2017. Since then, minor additions have been made, and will continue to be made, but these will not affect the fundamental structure of CoastAdapt.

The growing literature on decision support frameworks for adaptation acknowledges that if these frameworks are to be useful, used and long-lived, their development requires collaboration between creators and potential users (Romsdahl and Pyke 2009; Romsdahl 2011; Kopke and Dwyer 2016; Prokopy et al. 2017). Failure to collaborate creates the risk that the end product will itself be a barrier to adaptation, for example by being difficult to navigate, using jargon or failing to properly contextualise the information (Hewitson et al. 2017). For CoastAdapt, consultation took place at every point in design, development and delivery. Here, we describe those aspects 
that set out to understand and address user needs, and then to evaluate the extent to which CoastAdapt was successful in these attempts. A comprehensive overview of all engagement during the project, including the rationale for each strategy, specifics on activities, and the required resourcing, is provided in this Special Issue by Leitch et al. (submitted).

\section{Understanding user needs from CoastAdapt}

The primary mechanism to identify user needs from CoastAdapt in the pre-development phase was an open online survey held for 3 weeks in March 2015. This was advertised through the NCCARF website, newsletter and networks. The survey was backed up by 13 workshops held in major population centres across Australia. The survey was completed by 313 individuals. The workshops were attended by 330 people. There will be some crossover between the two categories.

Surveys are a common way to solicit information and opinion from managers, community groups and property owners concerned with adaptation, and have been used in Australia to understand the accessibility and value of information to practitioners (Kiem and Austin 2013; O’Toole and Coffey 2013; Kiem et al. 2014; Temby et al. 2016) and the use of planning measures to achieve adaptation goals (Gurran et al. 2013; Taylor et al. 2013). Phone interviews (Mills et al. 2016), email (Sciulli 2013), open online surveys (Kiem and Austin 2013), workshops (Taylor et al. 2013), focus groups (Bates et al. 2013), semi-structured interviews (O’Toole and Coffey 2013) or some combination (Gurran et al. 2013; Kiem et al. 2014) have all been employed, with sample sizes ranging from fewer than 30 (Sciulli 2013) to over 400 (Mills et al. 2016). Here, we used an online approach, as providing a fast, low-cost and structured means of gathering information. We advertised the survey widely and intensively to potential CoastAdapt user groups. By asking a set of preliminary questions about respondents' type of work and level in the organisation, we were able to focus the analysis on responses from potential users of CoastAdapt.

The survey consisted of 14 questions (see Supplementary Material). People are time-poor, so the questions were designed to be straightforward and relatively quick to answer. Only three were open ended. The remaining questions had 10-15 possible answers, and directed respondents to choose the three they considered most relevant. An 'Other' category was always included to enable respondents to provide more information.

The first four questions identified respondents' place of work, location and role. Sixty-nine respondents identified as working or studying at university or school. For the purpose of understanding user needs from CoastAdapt, these were excluded, leaving 244 surveys available for further analysis. Around two thirds of the 244 were employed in government, of which about half were in local councils (a target group for CoastAdapt). The remaining third were split evenly between consultants and business/industry, with a small percentage from community groups and non-governmental organisations. Note that consultants were counted separately from business/ industry because councils often employ a consultant to conduct 'one-off' tasks such as preparation of an adaptation plan. As such, consultants are likely to be important users of CoastAdapt.

We asked people to describe their level or role within their organisation. The largest category was middle management (30\%), followed by policy analyst/advisor (25\%) and senior management (19\%). Respondents were geographically representative but, whereas Victoria was under represented (13\% of survey respondents but $25 \%$ of the Australian population), Queensland, South Australia and Tasmania were overrepresented (with 28, 15 and 8\% of respondents respectively, compared to 20,7 and $2 \%$ of the population). For all other states/ territories, the proportion of respondents reflected their proportion of the national population. 
Thus, overall, with respect to their location, place of work and job level, survey respondents were broadly representative of the types of users we sought to target with CoastAdapt, and their views form a critical component of the design process. Here, we explore in detail four questions from the survey. The first is scene-setting, asking respondents to name the impacts they consider to be the most important. The second asks them to describe the barriers to progress in planning for action to address these impacts. This is the only one of the four questions reviewed here that was open-ended; given the large literature on adaptation barriers we were interested to understand respondents' perceptions in the absence of any prompts. The third then focusses on knowledge gaps and, leading on from this, the final question asked respondents to identify the content they considered most important to include in CoastAdapt.

What are the most important impacts resulting from climate change and sea-level rise that you believe coastal organisations must address? Please tick up to three As shown in Fig. 1, increased risk of storm surge and inundation came across as the most important impact for all respondents, followed by (in order) impacts on ecosystems and biodiversity, increased occurrence of extreme events, and increased erosion and beach loss. Different groups had different priorities - this ordering of importance reflects in part the dominance of government respondents. When we look at non-government respondents we find, for example, that industry/business is concerned about impacts on property values, and is the group most concerned about difficulties in obtaining insurance as a result of climate change, although for all groups this is a relatively minor consideration. The greatest concern for industry/business is increased occurrence of extreme events, probably reflecting risks to

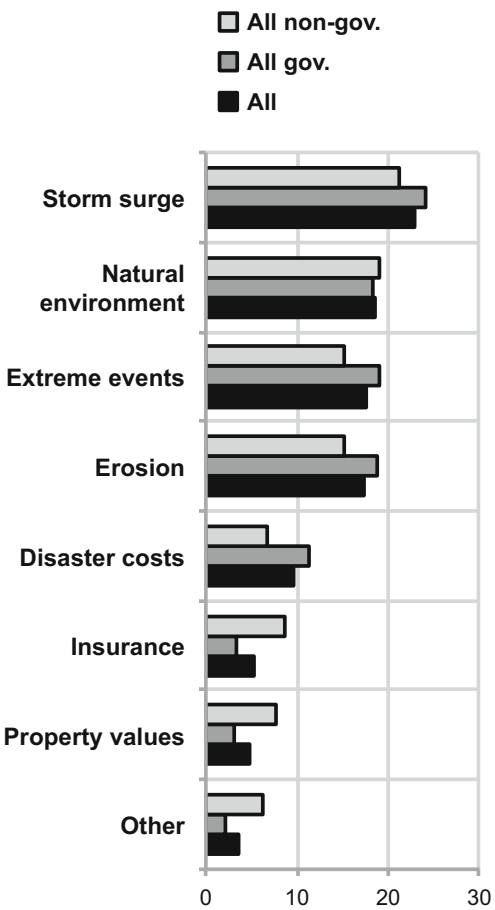

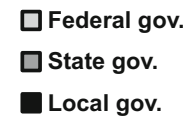

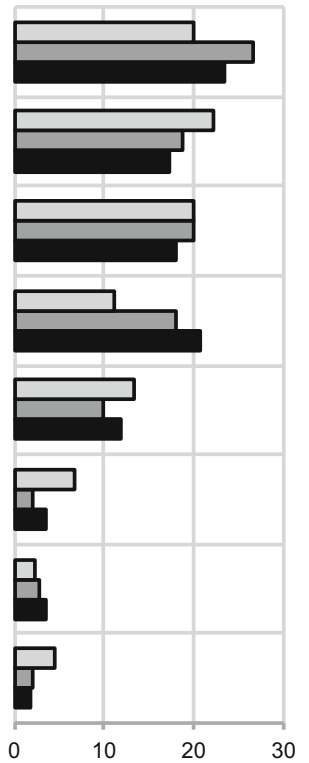

$\square$ Community org.

$\square$ Consultants

Industry/business

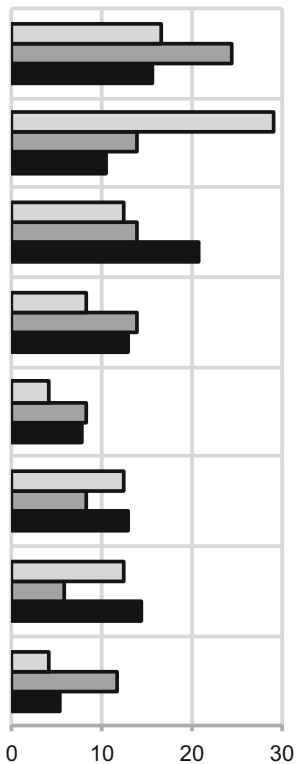

Fig. 1 Survey responses (\%) to question 'What are the most important impacts resulting from climate change and sea-level rise that you believe coastal organisations must address? Please tick up to three' 
business continuity and supply and delivery chains (Wedawatta and Ingirige 2012; Jaroszweski et al. 2015). The 'Other' category, with 25 responses out of 678, did not reveal any consistent concerns, although a number of respondents observed that multiple interacting impacts from climate change pose the greatest risks.

What do you consider to be the single most important barrier to progress on planning for climate change in the coastal zone? This was an open-ended question. Responses were inspected and could be classified into 12 groups, as shown in Fig. 2. For this question, there are only 236 responses for analysis ( 8 chose not to respond). By far the most common response (27\%) was related to failure of leadership. Typical comments are 'Governments and influential individuals and organisations unwilling to engage in and support adaptation strategies' and 'Lacking a consistent position on climate change across all levels of government'. The next most common barrier, scientific uncertainty/lack of knowledge, had only $12 \%$ of all responses. Broken down by employer, responses show a more complex picture. It is government employees who are concerned about lack of leadership. For industry/ business the main barrier is vested interests, most commonly seen as developers and owners of expensive beachfront properties. Typical comments are 'Industry expectations of unfettered access to low lying and coastal areas for development' and 'Vested interests of coastal developers, development focused councils and coastal property owners'. For consultants, the main barrier is scientific uncertainty/lack of knowledge, closely followed by short time
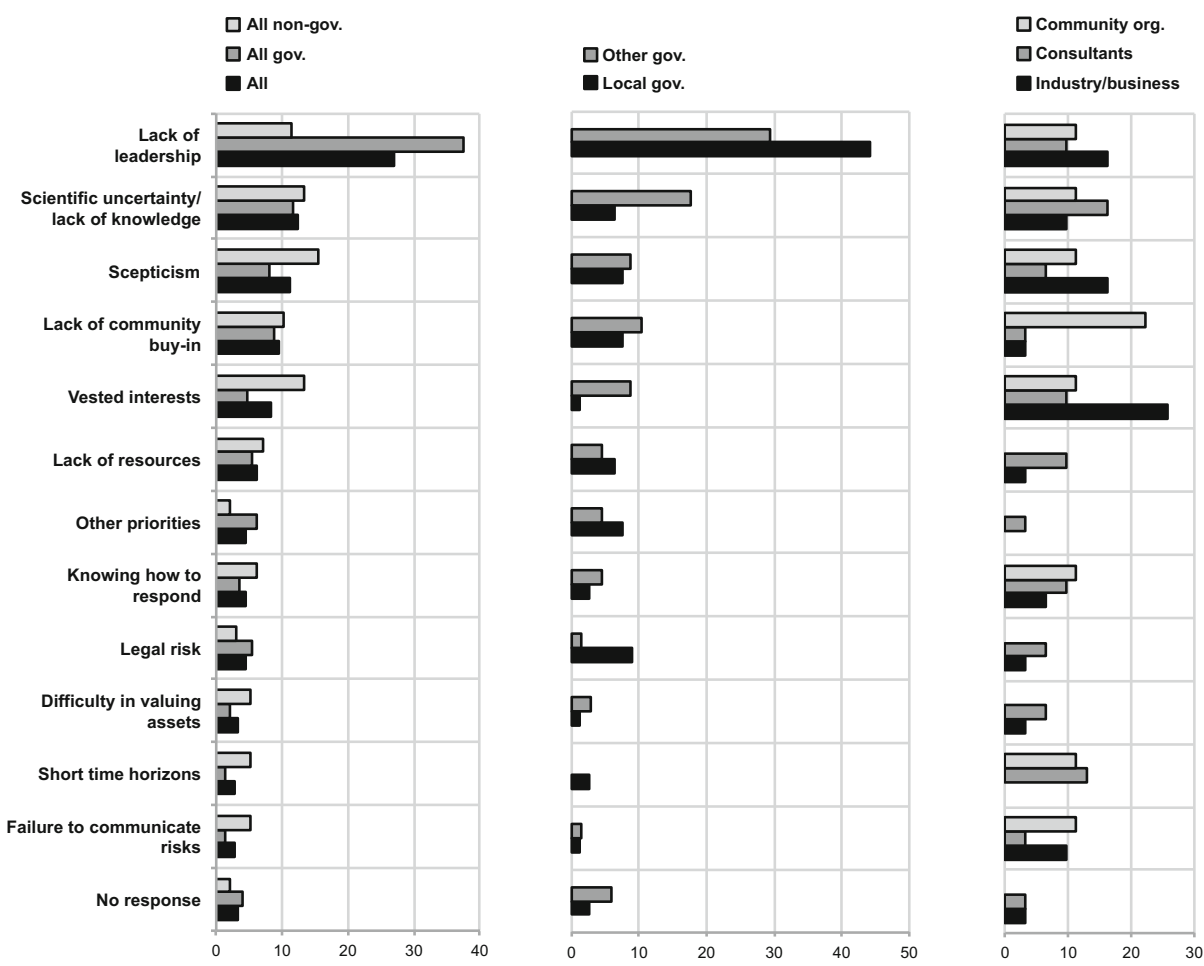

Fig. 2 Survey responses (\%) to question 'What do you consider to be the single most important barrier to progress on planning for climate change in the coastal zone?' Some respondent categories have been combined because of the smaller number of respondents $(n=236)$ 
horizons. Comments included 'Ensuring accurate expert opinions are checked and balanced, not just relying on U.N. decisions made thousands of kilometres away' and 'Poor understanding of what climate change really means at all levels of society and government'.

What knowledge gaps prevent the best possible decisions being made about present and future climate-related risks? Tick any that apply The third question (Fig. 3) moves away from the generality of barriers, including institutional and governance barriers that cannot be addressed by a decision support platform such as CoastAdapt, and towards a focus on knowledge-related barriers - the first step in thinking about how CoastAdapt could support more effective adaptation. There was strong support across all respondents for management options through defence, retreat and accommodation of sea-level rise and inundation, together with laws, planning and building regulations as these set the context for and affect climate risk management, and it was also felt there was a lack of knowledge around future climate change and flood risk. Present-day risks from extremes, present-day risk of flooding and engineering solutions received less support. This suggests that present-day risks are reasonably well understood, but future risks and possible solutions are not. Government respondents followed this pattern, although federal government employees also identified present-day risks from climate extremes as a knowledge gap — perhaps unsurprising given that federal government has shared responsibilities with states and territories for disaster management in Australia.
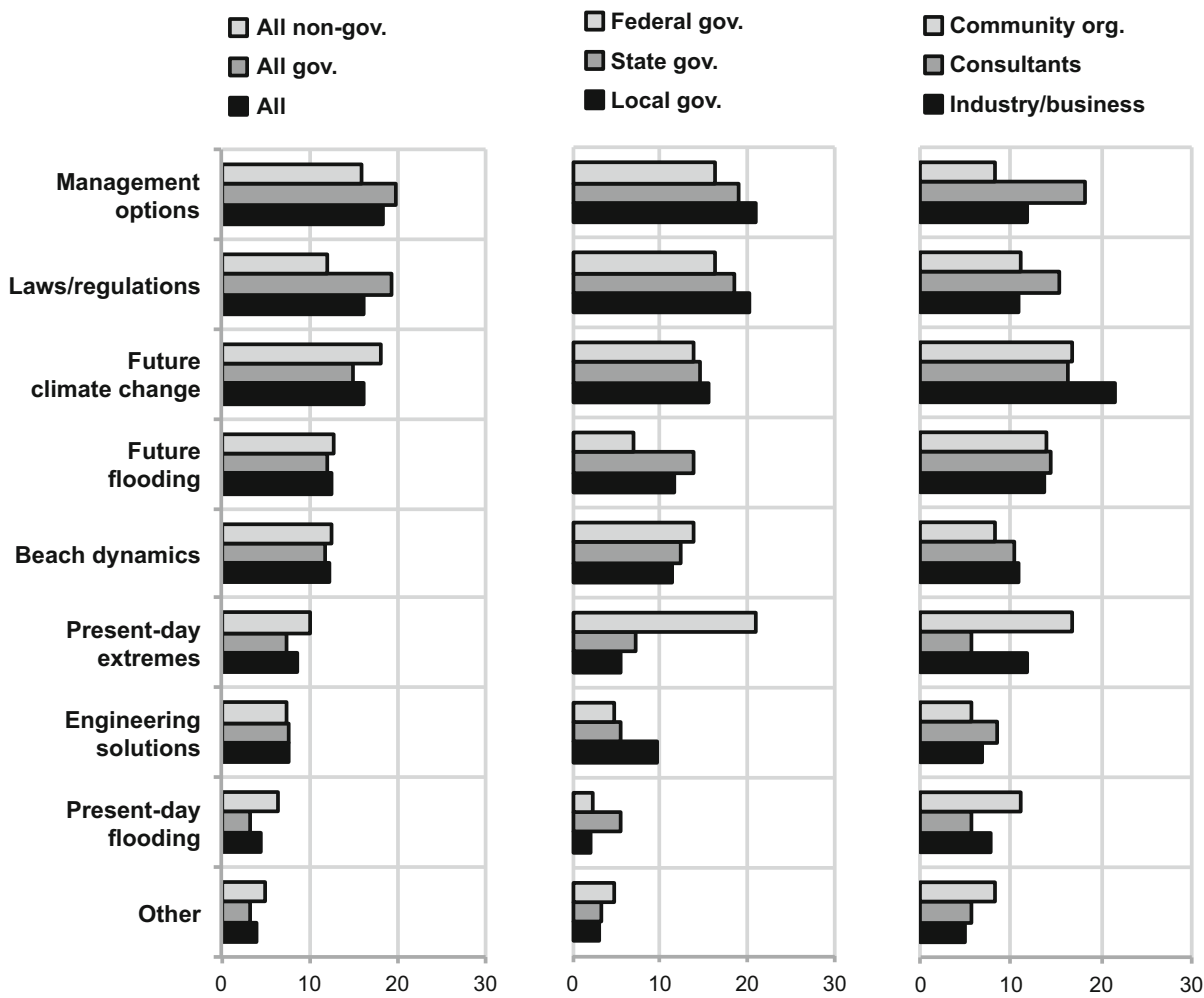

Fig. 3 Survey responses (\%) to question 'What knowledge gaps prevent the best possible decisions being made about present and future climate-related risks? Tick any that apply' 
What do you think are the key features of a coastal climate risk management tool that will make it useful for coastal decision makers? Please tick up to three The final question of the four requests the respondent to explicitly consider how CoastAdapt can support adaptation (see Fig. 4). Out of 15 possible responses, five were considered of great importance for potential CoastAdapt users. Respondents were clear that CoastAdapt should be authoritative (guidance should be developed, reviewed and approved by experts), should be tailored to
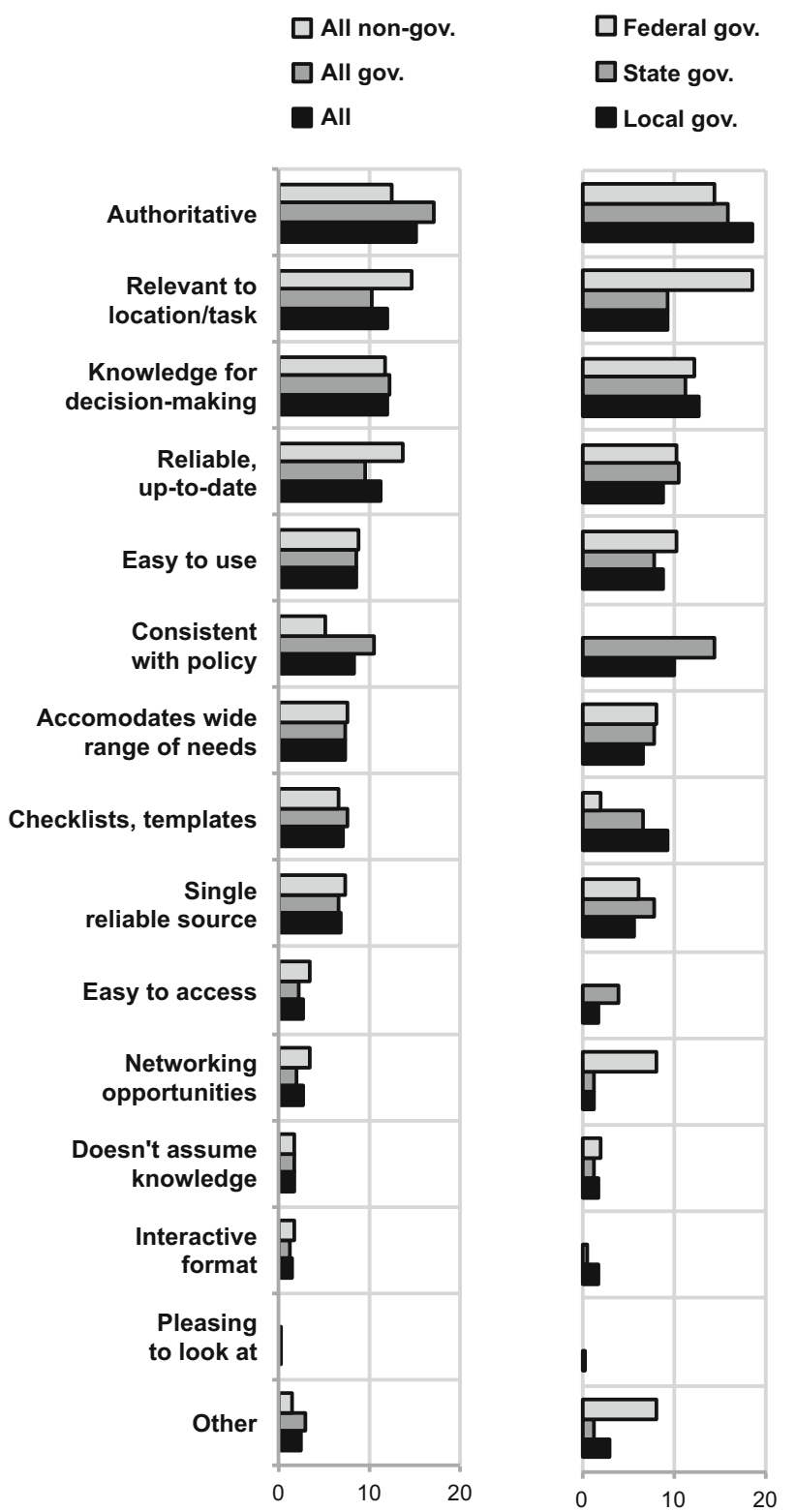

\section{$\square$ Community org. \\ $\square$ Consultants \\ Industry/business}

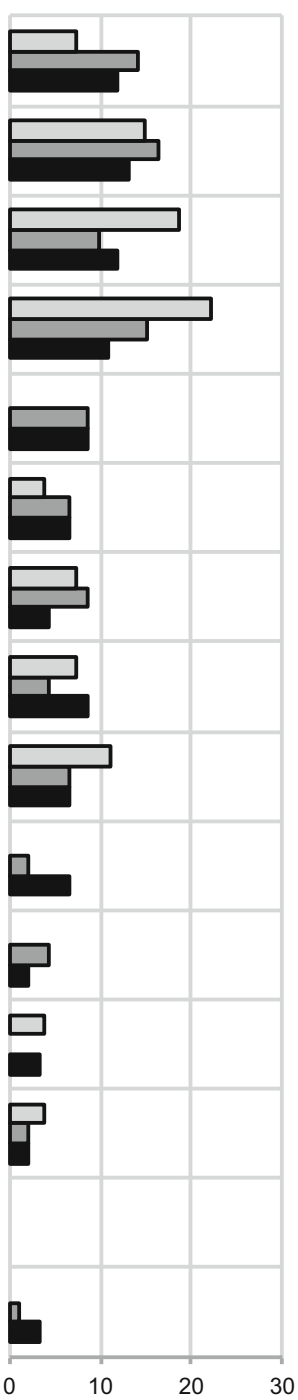

Fig. 4 Survey responses (\%) to question 'What do you think are the key features of a Coastal Climate Risk Management Tool that will make it useful for coastal decision makers? Please tick up to three' 
user location and requirements, and should provide the knowledge needed to make the best possible decisions. In addition, for state and local government respondents, it was important that the guidance provided in CoastAdapt should be consistent with policy. Respondents in the consultant and business/industry categories thought it important that the information in CoastAdapt should be reliable - based on up-to-date information and regularly updated. Four responses were not widely supported. These were that it should be interactive, be pleasing in appearance, provide opportunity for peer to peer sharing and learning, and should not assume too much starting knowledge. It is worth noting, however, that the feedback from the regional workshops did support provision of networking opportunities. In between, there was some support for the response that CoastAdapt should be easy/intuitive to use, easy to access through the Internet, be a single source of reliable information, provide checklists and templates to support decision-making (most strongly supported by local government respondents) and accommodate a wide range of user needs from introductory through to decisionmaking to address complex problems. Again, the regional workshops provided nuance: we found that in more remote locations there were strong concerns about ability to access CoastAdapt content because of slow and unreliable Internet connections. Finally, 17 respondents ticked the 'Other' category. The commonest responses spoke to the need to establish the authoritativeness of CoastAdapt, so that users would feel confident to use it. Some asked for very specific content to be included — around risk analysis and local datasets, for example.

\section{Production and review of the beta version of CoastAdapt}

The survey results, together with the feedback received from the workshops, enabled us to compile a 'wish list' of design and content features that should be addressed in order to fulfil stated user needs. Table 1 summarises this wish list, and the actions that were taken in response within the initial design and build process of CoastAdapt.

We worked with users in a number of ways throughout the design and development of material for CoastAdapt. A user panel was set up to guide the selection of material to include in CoastAdapt. All content in CoastAdapt was subject to formal expert review, and evaluated by user groups for its usability and usefulness. A full description of these strategies for user involvement is provided by Leitch et al. (submitted).

The beta version was completed in June 2016 and was made public for consultation and review in July. User feedback was obtained through three mechanisms. The first was a questionnaire with 47 questions, taking respondents through each component of CoastAdapt and asked them via a seven-point Likert scale to express how much they agreed or disagreed with a statement such as 'CoastAdapt's search feature is easy to use'. These Likert scale questions were interspersed with open-ended questions, for example, 'Are there other topics that should be covered by the Information Manuals?'. The second was a blank feedback form accessed via a clickable tab on the right-hand margin of each web page. Finally, we ran consultation meetings across Australia in all state capitals as well as regional centres.

In total, there were 292 responses to the questionnaire, 51 feedback messages, and 395 people attended consultation meetings. However, these are not unique responses - the agenda for the consultation meetings included time for people to look at CoastAdapt and fill in the questionnaire. All but three of the respondents using the feedback tab left their name, and generally are not people who attended the workshops. Thus, at least 443 people were reached through the consultation. 
Table 1 User needs from CoastAdapt and how these were addressed. (SLR = sea-level rise)

Top four answers to each question

How addressed in CoastAdapt?

Q1: What are the most important impacts resulting from climate change and sea-level rise that you believe coastal organisations must address?

Increased risk of storm surge and marine inundation

For each coastal council where LiDAR data available, inundation maps are provided for 2050 (RCP8.5) and 2100 (RCP4.5, RCP8.5)

Impacts of climate change on the coastal, estuarine and terrestrial environment

- 13 sector-based 'impact sheets' provide information on impacts in the coastal zone

- Short reports on waves, water levels, and estuarine impacts are provided

Increased frequency and/or magnitude of extreme climate events

- CoastAdapt includes a webpage on ocean acidification

- For each coastal council, timelines of the future evolution of two extreme temperature metrics and two extreme rainfall metrics to 2100 are presented

- CoastAdapt contains a webpage on tropical and extratropical storms including a review of the literature on their future evolution

Increased risk of coast erosion and beach loss

Qualitative evaluation of the geomorphology of the coastline and its erodibility are provided at resolutions sufficient for a first-pass risk assessment

Q2: What do you consider to be the single most important barrier to progress on planning for climate change in the coastal zone?

Lack of government leadership

Scientific uncertainty/lack of knowledge

Out of scope

CoastAdapt is a comprehensive information library for coastal adaptation; it contains guidance on how to evaluate model-derived scenarios of future climate change and sea-level rise

Scepticism

CoastAdapt provides information and guidance on how to build a business case for adaptation, how to obtain organisational buy-in, and how to engage with communities and gain community support

Lack of community buy-in

CoastAdapt provides information and guidance on how to engage with communities and gain community support

Q3: What knowledge gaps prevent the best possible decisions being made about present and future climate-related risks?

Management options for sea-level rise risks (strategies to avoid, accommodate, protect, retreat)

Future climate change in the local area

Extensive information in CoastAdapt at different levels of complexity, from a one-page infographic on 'What are the options for adapting to sea level rise?' to an Information Manual on 'Engineering Solutions for Coastal Infrastructure'

- Users are directed to the Climate Change in Australia website for scenarios of mean change.

- Timelines of the future evolution of two extreme temperature metrics and two extreme rainfall metrics to 2100 are presented.

Laws, planning and building regulations as these affect risk management

- CoastAdapt contains an Information Manual on Legal Risk. There is a webpage on jurisdictional differences between the states

- Individual webpages prepared by each state present information on their adaptation-relevant legislation, policy and available data

Future risk of flooding

- For each coastal council where LiDAR data available, inundation maps are provided for 2050 (RCP8.5) and 2100 (RCP4.5, RCP8.5) 
Table 1 (continued)

Top four answers to each question

How addressed in CoastAdapt?

- Landsat imagery maps of surface water observations indicate areas of present-day vulnerability to flooding and hence areas of future risk

Q4: What do you think are the key features of a Coastal Climate Risk Management Tool that will make it useful for coastal decision makers?

Is authoritative: gives guidance that has been developed, reviewed and approved by experts

Provides information tailored to location and requirements

Provides the knowledge needed to make the best possible decisions

Over half CoastAdapt content has been developed by external experts; all CoastAdapt content is reviewed by external experts; CoastAdapt has been approved by state and federal government representatives

Datasets for present-day vulnerability (erosion and flooding potential) and future climate, SLR and inundation risk are all presented at a resolution no coarser than local council level

All content in CoastAdapt is evaluated by user groups to ensure it meets their needs; during review and consultation of the beta version users were asked to identify any gaps - these were addressed where feasible in the final version

Is reliable - is based on up-to-date information and is regularly updated

- Biannual survey of states to ensure policy information remains current

- Biannual review of links

Perhaps the most useful question in the beta version questionnaire proved to be 'What is the worst thing about CoastAdapt?'. Analysis of the 183 responses to this open-ended question shows that the commonest response is related to the volume of material contained in CoastAdapt, and difficulties associated with its navigation. Forty-nine of the 183 responses (27\%) related to difficulties for first-time and infrequent users with navigation, using words like 'daunting' and 'overwhelming'. A typical phrase was 'a bit hard to know where and how to start'. The next most common set of responses (35, or 19\%) concerned the long-term future of CoastAdapt - in terms of capacity to keep updating and renewing it, and also funding arrangements. Although this was not an issue to be addressed at this stage, it is interesting that it forms an early and important concern of potential users. Twenty-two (12\%) respondents had various remarks about the datasets in CoastAdapt: common concerns included that the shape files of the inundation mapping were not available for download into a GIS, that places where LiDAR data are known to be available are not included in the inundation mapping, and that CoastAdapt lacked data on future climate change. Twelve respondents $(7 \%)$ pointed to the tension between CoastAdapt, which is a national resource taking a national perspective on coastal adaptation, and the decision-making context for many coastal planners and managers, which is determined by each state's regulatory and legislative frameworks. Finally, five respondents commented on the poor experience of using CoastAdapt on a tablet or smartphone around both navigation and display, and five remarked that CoastAdapt was text heavy.

All comments received during the beta version consultation, from the open-ended questions in the questionnaire, from remarks made in consultation meetings, and from the feedback tab, were entered into a spreadsheet. They were then evaluated to determine whether they (a) could usefully be addressed through modification/addition to CoastAdapt in the time available or (b) could usefully be addressed at some future date if additional funding were available or (c) were out of scope (for example, relating to lack of certainty around long-term funding) or (d) did not require addressing (for example, positive remarks about CoastAdapt). 
In addition to general updating and checking and fixing broken links, we made 12 major changes to CoastAdapt in response to comments and suggestions made during consultation, in three categories. The first category is around the datasets in CoastAdapt, and the changes were as follows:

- For each local council, we added projections of five temperature and rainfall extremes related to hot days, warm nights, heatwaves, intense rainfall events and droughts. These were for four future time slices centred on 2030, 2050, 2070 and 2090.

- In response to comments that the inundation maps were hard to interpret because the flooding overlay obscured geographical features on the satellite-derived basemaps, the maps were redrawn using a topographic map as the background.

- Postcode searching was added to the search facility for Sea-level Rise and You, which was initially only by local council name, because some council names are neither familiar nor intuitive.

- A guide to coastal hazard mapping for coastal managers, with a particular focus on scalerelated issues, was added.

- Finally, we provided higher resolution versions of the historical time series of sea level derived from satellite data.

The second category of changes addresses expressed issues around ease of navigation, especially for first-time and infrequent users, as follows:

- A new button, Getting Started, was added to the home page. This links to a video introducing CoastAdapt and its capabilities and to some role-specific suggestions about useful material in CoastAdapt that users might like to explore.

- The cross-referencing between webpages, using a sidebar, was improved in an effort to draw the attention of users to other material relevant to them.

- The 'About CoastAdapt' webpage was rewritten to give a more expansive introduction to CoastAdapt — what it can do, why people should use it and what it contains. The webpage now contains a video explaining why CoastAdapt was built, giving some real-life examples of how it has proved useful to coastal managers.

- The navigation through C-CADS, the risk management framework in CoastAdapt, was improved.

Finally, users requested material more precisely targeted to their needs. First, they identified a need for more case studies, with an emphasis on adaptation action rather than adaptation planning. Twelve new case studies have been added post consultation, bringing the total to 81 . Second, they asked for more straightforward, simpler explanations of key topics, which should be light on text and well-illustrated. Six new infographics were added, explaining topics such as coastal processes, risk assessment, flood probabilities and CoastAdapt's inundation maps. Third, they asked for more 'hands-on' material that they could use to undertake adaptation tasks and track their progress. We added checklists to C-CADS to self-assess progress through the risk management framework. Existing templates, for example around working with consultants, were converted into clickable pdfs and a new template was added on evaluating a consultant's performance. Given time, we would add more 'hands-on' material, as this appears to be particularly valued by users. 


\section{Effectiveness in 'real-world' adaptation}

Reactions to both the beta and final versions were very positive, almost without exception. What was lacking, however, was in-depth analysis of CoastAdapt performance by users. To better understand how it could be used to address 'real-life' adaptation problems, and the extent to which it offered value to users, two series of six-week test cases were commissioned, as summarised in Table 2. Round 1 test cases were conducted during consultation and review, and so were based on the beta version of CoastAdapt. Round 2 test cases took place as the final version of CoastAdapt was awaiting release, and participants were given access to the final version under conditions of confidentiality.

In round 1, we sought recommendations from trusted stakeholders and invited groups to participate. In round 2, an open call was made via the NCCARF website and newsletter, and interested groups were asked to complete a proposal setting out an adaptation problem they could address with support from CoastAdapt. Each project was provided with a consultant (unaffiliated to NCCARF) to guide their use of CoastAdapt and received a small amount of money, mainly to legitimise their participation in the eyes of the parent organisation, and to pay for any marginal project costs. Projects provided short case studies that are now included in CoastAdapt. Final reporting required an evaluation of CoastAdapt performance, and asked for suggestions regarding possible improvements.

Overall, test case participants were positive about CoastAdapt in their final reports. For example, the North Queensland Airports test case stated that Coast Adapt was 'very successful in providing ... a comprehensive risk register' and Noosa Council called it an 'excellent source of information about climate change and climate change adaptation'. Participants offered useful suggestions for improvements and, for the round 1 test cases, some of these could be implemented. There were some negative comments in both rounds of test cases about difficulties of navigating CoastAdapt, despite efforts to improve navigation between the beta and final versions. The comments also provide some interesting insights into where CoastAdapt might go next, with requests to better address the needs of the private sector and to include more material relevant to Indigenous people, especially Traditional Owners of coastal land.

\section{Discussion}

We set out to design and build a decision support and information delivery framework for coastal adaptation in Australia. From the outset, we recognised the need to involve potential users at every stage, in order to ensure that CoastAdapt would be known and accepted as useful and usable by the adaptation community.

The initial consultation revealed a number of user needs, including provision of information, data and guidance that could be addressed by a well-structured, comprehensive and targeted framework such as CoastAdapt. We aimed to address these needs through key features in CoastAdapt such as the design, which seeks to be attractive and easily-navigable; the content, selected to address expressed user needs; and the delivery, with a minimum of technical language and at three levels of depth and detail. However, the initial consultation also revealed a number of adaptation barriers beyond the scope of CoastAdapt to address, including lack of leadership in adaptation, lack of resources and vested interests (generally, around property development). Such barriers require cultural and political change if they are to 


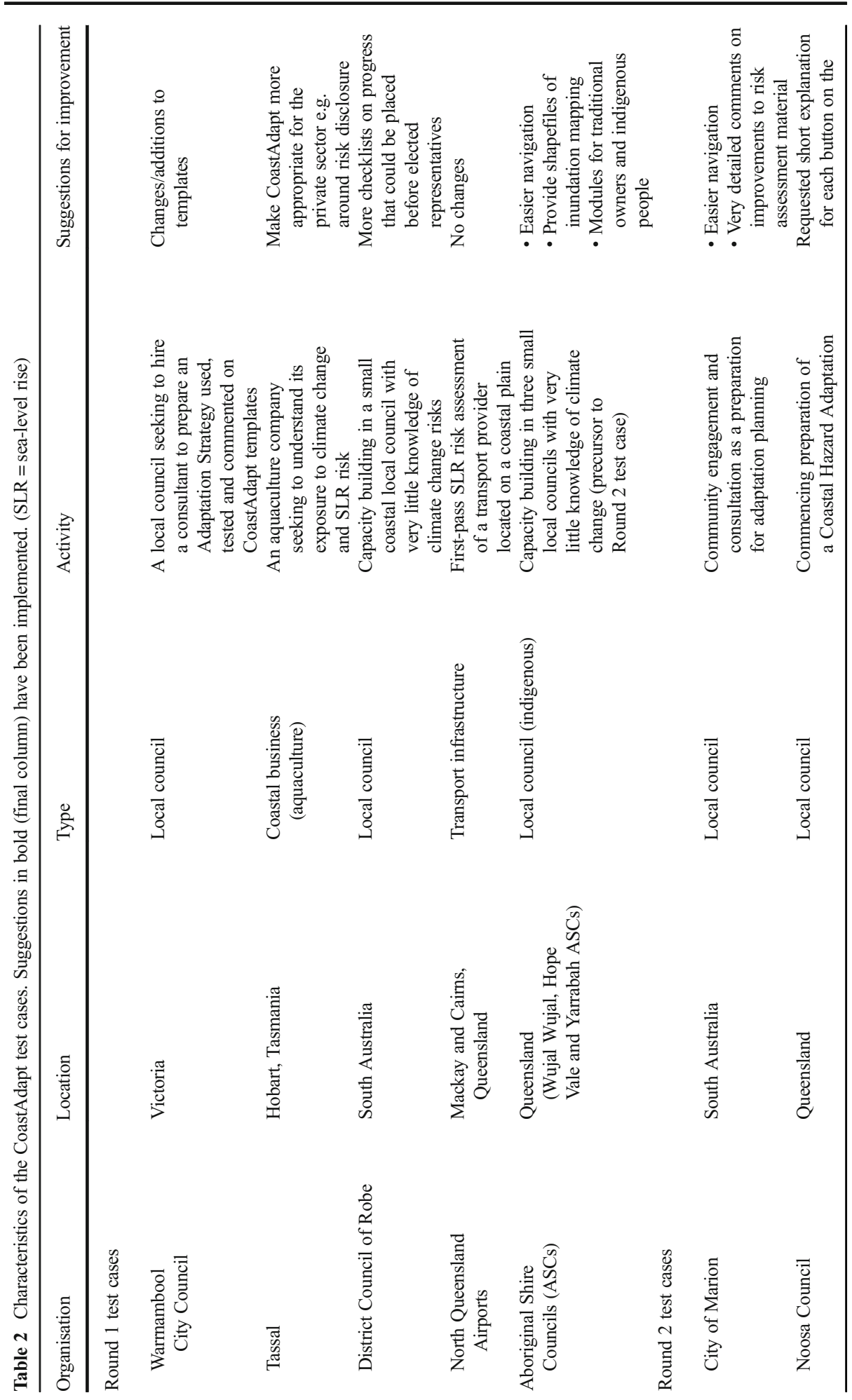




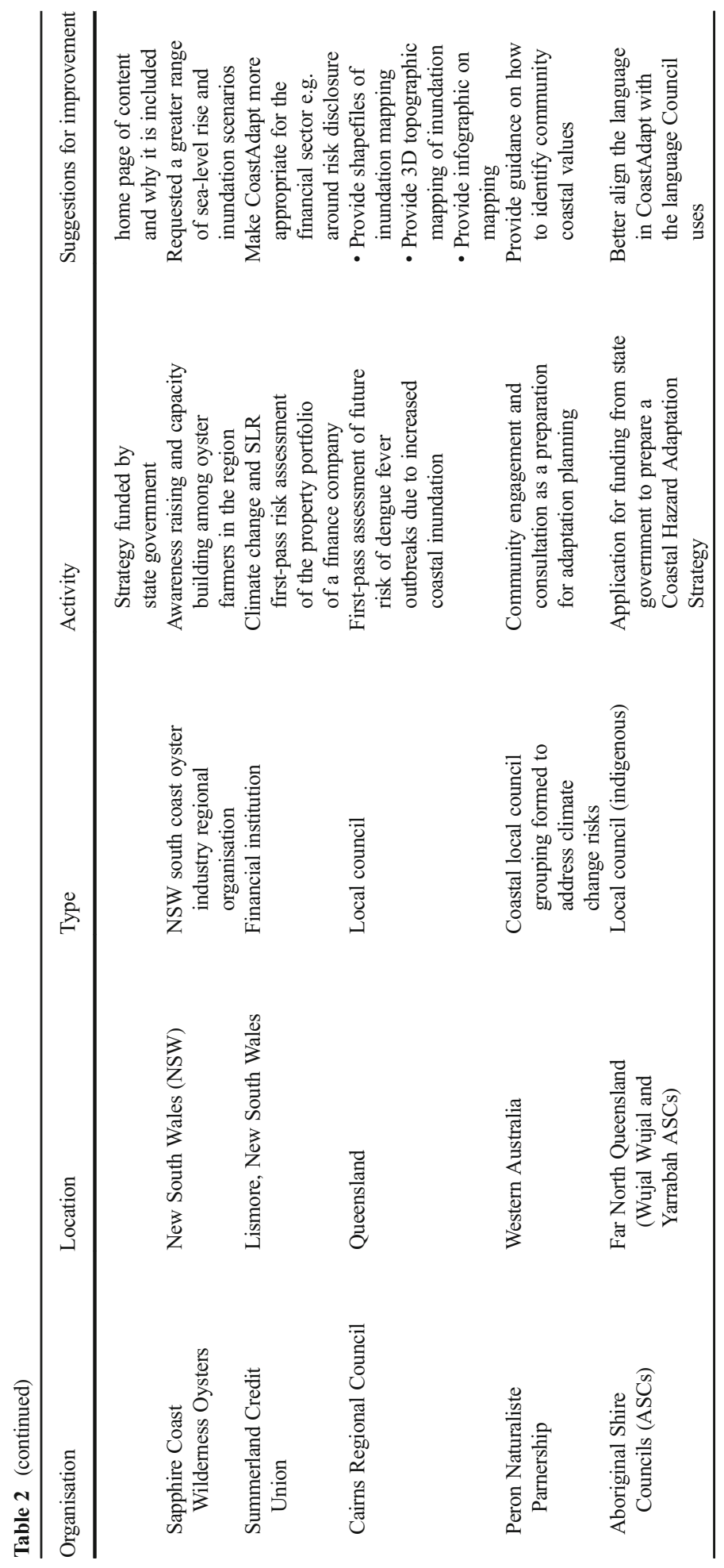


be overcome (Mukheibir et al. 2013; Sciulli 2013; Mills et al. 2016), and so cannot be directly addressed by CoastAdapt. Recent initiatives by state governments in Australia are designed to provide financial support for coastal adaptation by local councils (e.g. LGAQ and DEHP 2016) and/or place a requirement on coastal local councils to plan for climate change (e.g. Parliament of New South Wales 2016). Where such leadership for coastal adaptation exists, decision support frameworks such as CoastAdapt have an important role to play in the provision of guidance and information.

Eleven six-week test cases enabled users to evaluate CoastAdapt performance in helping to solve real-world adaptation challenges. Essentially, these tested whether CoastAdapt could support users to overcome adaptation barriers related to lack of knowledge and guidance. Evaluation of the test cases suggests that CoastAdapt is especially successful at helping coastal managers at the initial stages of adaptation-seeking knowledge about climate change, potential impacts and strategies to address these. A number of test cases carried out firstpass risk assessments and one did a second-pass assessment, and all found the material in CoastAdapt appropriate and supportive.

Groups that are more advanced in adaptation, having reached a detailed planning stage, may find CoastAdapt to be less helpful. The test cases identified two main reasons for this. First, CoastAdapt is a national tool, whereas the policy, legislative and regulatory framings for coastal adaptation are largely set at the state level. This means that, for example, the planning benchmarks for sea-level rise are not the same in every state, and may change depending on the government in power. Against this background of uncertainty, CoastAdapt uses the representative concentration pathway scenarios (van Vuuren et al. 2011) as a basis for its sea-level rise projections. Although this is fine for initial exploration of risk, and for private sector users who do not have to work to state government benchmarks, it may limit local council use of CoastAdapt datasets for detailed adaptation planning. Second, the datasets in CoastAdapt are derived from national sources such as Geoscience Australia. Their spatial resolution may be considered insufficient for the needs of advanced adaptation planning. Especially in the case of the inundation mapping, they may not be fully up to date. Many states, local councils and private entities are commissioning LiDAR surveys as a basis for inundation mapping. This means that the CoastAdapt inundation maps are blank in places where local people know that LiDAR surveys have been carried out, and this in turn erodes trust.

Is it possible for CoastAdapt to address the needs of the adaptation community, from those just starting to consider the risks through to those well on the way with their planning and implementation, especially local councils needing to abide by state government settings? The answer may be no-CoastAdapt would simply become too cumbersome, too difficult to navigate, and too hard to keep updated if it tried to incorporate all state government requirements. In the Australian context, where there remain many small coastal local councils and businesses that have barely begun to think about adaptation, CoastAdapt fulfils an important role. Moreover, for entities which are not constrained by state government requirements, CoastAdapt provides a wide range of material relevant to all stages of adaptation.

\section{Conclusions}

We have created a decision support and information delivery framework that seeks to address the needs of the coastal adaptation community in Australia at the present time. Usage (tracked in Google Analytics) has grown steadily since final release, achieving 4130 users and 5061 
sessions in November 2017. Against this background of continuing interest, a concern for CoastAdapt, shared by many decision support frameworks and data delivery systems (Moran et al. 2009), is the availability of resources for its continuing maintenance and development. NCCARF has been provided with Australian Government support to explore sustainable funding strategies for CoastAdapt, and is currently working to identify, evaluate and implement potential funding mechanisms.

Adaptation is a rapidly changing field of activity and CoastAdapt must change and grow to meet evolving user needs. In the short-term, perhaps 2 to 3 years ahead, the most important requirement will be to keep CoastAdapt up to date in terms of climate change science (especially, sea-level rise) and changes in relevant national and state-level policy, legislation and regulation. Failure to do so will lead to a rapid decline in users. In the longer term, there will be a need to address the (hopefully) more in-depth requirements of adaptors as they move towards evaluating options, building and implementing plans, and monitoring and evaluating results. Whether that can be achieved by a single framework such as CoastAdapt, or whether given the constitutional arrangements in Australia there needs to be a set of state-based frameworks, perhaps in some kind of hub and spoke arrangement with a core of common knowledge and guidance at the hub, remains to be tested.

Acknowledgements The authors thank the reviewers for their insightful and constructive comments. CoastAdapt was funded by the Australian Government through the Department of the Environment and Energy. The views expressed in this paper are not necessarily the views of the Commonwealth of Australia and the Commonwealth does not accept responsibility for information or advice it contains.

Open Access This article is distributed under the terms of the Creative Commons Attribution 4.0 International License (http://creativecommons.org/licenses/by/4.0/), which permits unrestricted use, distribution, and reproduction in any medium, provided you give appropriate credit to the original author(s) and the source, provide a link to the Creative Commons license, and indicate if changes were made.

\section{References}

Baker I, Peterson A, Brown G, McAlpine C (2012) Local government response to the impacts of climate change: an evaluation of local climate adaptation plans. Landsc Urban Plan 107:127-136. https://doi.org/10.1016/j. landurbplan.2012.05.009

Barnett J, Evans LS, Gross C et al (2015) From barriers to limits to climate change adaptation: path dependency and the speed of change. Ecol Soc 20(3):5. https://doi.org/10.5751/ES-07698-200305

Bates LE, Green M, Leonard R, Walker I (2013) The influence of forums and multilevel governance on the climate adaptation practices of Australian organizations. Ecol Soc 18:62. https://doi.org/10.5751/ES-06120180462

Chen K, McAneney J (2006) High-resolution estimates of Australia's coastal population. Geophys Res Lett 33 : L16601. https://doi.org/10.1029/2006GL026981

DCC (2009) Climate change risks to Australia's coast: a first pass national estimate. Department of Climate Change, Australian Government, Canberra. http://www.environment.gov.au/system/files/resources/fa553 e97-2ead-47bb-ac80-c12adffea944/files/cc-risks-full-report.pdf. Accessed 22 August 2017

Fletcher CS, Rambaldi AN, Lipkin F, McAllister RRJ (2016) Economic, equitable and affordable adaptations to protect coastal settlements against storm surge inundation. Reg Environ Chang 16:1023-1034. https://oi. org/10.1007/s10113-015-0814-1

Gurran N, Norman B, Hamin E (2013) Climate change adaptation in coastal Australia: an audit of planning practice. Ocean Coast Manag 86:100-109. https://doi.org/10.1016/j.ocecoaman.2012.10.014

Harman BP, Heyenga S, Taylor BM et al (2015) Global lessons for adapting coastal communities to protect against storm surge inundation. J Coast Res 31:790-801. https://doi.org/10.2112/JCOASTRES-D-1300095.1 
Henstra D (2017) Climate adaptation in Canada: governing a complex policy regime. Rev Policy Research 34: 378-399. https://doi.org/10.1111/ropr.12236

Herrmann J, Guenther E (2017) Exploring a scale of organisational barriers for enterprises' climate change adaptation strategies. J Clean Prod 160:38-49. https://doi.org/10.1016/j.jclepro.2017.03.009

Hewitson B, Waagsaether K, Wohland J et al (2017) Climate information websites: an evolving landscape. WIREs Clim Change 8:e470. https://doi.org/10.1002/wcc.470

Jaroszweski D, Hooper E, Baker C et al (2015) The impacts of the 28 June 2012 storms on UK road and rail transport. Meteorol Appl 22:470-476. https://doi.org/10.1002/met.1477

Kiem AS, Austin EK (2013) Disconnect between science and end-users as a barrier to climate change adaptation. Clim Res 58:29-41. https://doi.org/10.3354/cr01181

Kiem AS, Verdon-Kidd DC, Austin EK (2014) Bridging the gap between end user needs and science capability: decision-making under uncertainty. Clim Res 61:57-74. https://doi.org/10.3354/cr01243

Knutson TR, Sirutis JJ, Zhao M et al (2015) Global projections of intense tropical cyclone activity for the late twenty-first century from dynamical downscaling of CMIP5/RCP4.5 scenarios. J Clim 28:7203-7224. https://doi.org/10.1175/JCLI-D-15-0129.1

Kopke K, Dwyer N (eds) (2016) ICAN - best practice guide to engage your coastal web atlas user community. Manuals and guides 75, intergovernmental oceanographic commission of UNESCO, Paris. http://unesdoc. unesco.org/images/0024/002470/247004e.pdf. Accessed 7 November 2017

LGAQ and DEHP (2016) QCoast2100: councils leading coastal adaptation. LGAQ and Department of Environment and Heritage Protection, Brisbane. http://www.qcoast2100.com.au/. Accessed 17 January 2018

Marshall N, Stokes CJ (2014) Identifying thresholds and barriers to adaptation through measuring climate sensitivity and capacity to change in an Australian primary industry. Clim Chang 126:399-411. https://doi.org/10.1007/s10584-014-1233-x

McInnes KL, White CJ, Haigh I et al (2016) Natural hazards in Australia: sea level and coastal extremes. Clim Chang 139:69-83. https://doi.org/10.1007/s10584-016-1647-8

Measham TG, Preston BL, Smith TF et al (2011) Adapting to climate change through local municipal planning: barriers and challenges. Mitig Adapt Strateg Glob Change 16:889-909. https://doi.org/10.1007/s11027-011-9301-2

Mees H (2017) Local governments in the driving seat? A comparative analysis of public and private responsibilities for adaptation to climate change in European and North-American cities. J Environ Policy Plan 19: 374-390. https://doi.org/10.1080/1523908X.2016.1223540

Mills M, Mutafoglu K, Adams VM et al (2016) Perceived and projected flood risk and adaptation in coastal Southeast Queensland, Australia. Clim Chang 136:523-537. https://doi.org/10.1007/s10584-016-1644-y

Moran MS, Hutchinson BS, Marsh SE et al (2009) Archiving and distributing three long-term interconnected geospatial data sets. IEEE Trans Geosci Remote Sens 41:59-71. https://doi.org/10.1109 /TGRS.2008.2002815

Mukheibir P, Kuruppu N, Gero A, Herriman J (2013) Overcoming cross-scale challenges to climate change adaptation for local government: a focus on Australia. Clim Chang 121:271-283. https://doi.org/10.1007 /s10584-013-0880-7

Oberlack C (2017) Diagnosing institutional barriers and opportunities for adaptation to climate change. Mitig Adapt Strateg Glob Change 22:805-838. https://doi.org/10.1007/s11027-015-9699-z

O'Toole K, Coffey B (2013) Exploring the knowledge dynamics associated with coastal adaptation planning. Coast Manag 41:561-575. https://doi.org/10.1080/08920753.2013.848747

Parliament of New South Wales (2016) Coastal Management Bill 2016 (NSW). https://www.parliament.nsw.gov. au/bill/files/3291/Passed\%20by\%20both\%20Houses.pdf. Accessed 17 January 2018

Prokopy LS, Carlton JS, Haigh T et al (2017) Useful to usable: developing usable science for agriculture. Climate Risk Management 15:1-7. https://doi.org/10.1016/j.crm.2016.10.004

Romsdahl RJ (2011) Decision support for climate change adaptation planning in the US: why it needs a coordinated internet-based practitioner's network. Clim Chang 106:507-536. https://doi.org/10.1007 /s10584-010-9947-x

Romsdahl RJ, Pyke CR (2009) What does decision support mean to the climate change research community? Clim Chang 95:1-10. https://doi.org/10.1007/s10584-008-9538-2

Sciulli N (2013) Organizational barriers to adapting infrastructure assets to climate change: evidence from coastal councils in Australia. Public Money Manag 33:153-160. https://doi.org/10.1080/09540962.2013.763436

Taylor BM, Harman BP, Inman M (2013) Scaling-up, scaling-down, and scaling-out: local planning strategies for sea-level rise in New South Wales, Australia. Geogr Res 51:292-303. https://doi.org/10.1111/17455871.12011

Temby O, Sandall J, Cooksey R, Hickey GM (2016) How do civil servants view the importance of collaboration and scientific knowledge for climate change adaptation? Australasian J Environ Manag 23:5-20. https://oi. org/10.1080/14486563.2015.1028111 
The World Bank Group (2017) Table 3.12 World Development Indicators: Urbanization. http://wdi.worldbank. org/table/3.12. Accessed 22 August 2017

van Vuuren DP, Edmonds J, Kainuma M et al (2011) The representative concentration pathways: an overview. Clim Chang 109:5-31. https://doi.org/10.1007/s10584-011-0148-Z

Walsh K, White CJ, McInnes K et al (2016) Natural hazards in Australia: storms, wind and hail. Clim Chang 139: 55-67. https://doi.org/10.1007/s10584-016-1737-7

Wang C-H, Baynes T, McFallan S et al (2016) Rising tides: adaptation policy alternatives for coastal residential buildings in Australia. Struct Infrastruct Eng 12:463-476. https://doi.org/10.1080/15732479.2015.1020500

Waters E, Barnett J, Puleston A (2014) Contrasting perspectives on barriers to adaptation in Australian climate change policy. Clim Chang 124:691-702. https://doi.org/10.1007/s10584-014-1138-8

Webb RJ, McKellar R, Kay R (2013) Climate change adaptation in Australia: experience, challenges and capability development. Australas J Environ Manag 20:320-337. https://doi.org/10.1080 $/ 14486563.2013 .835285$

Wedawatta G, Ingirige B (2012) Resilience and adaptation of small and medium-sized enterprises to flood risk. Disaster Prev Manag 21:474-488. https://doi.org/10.1108/09653561211256170 